\title{
Oxygen saturation and breathing patterns in infancy. 2: Preterm infants at discharge from special care
}

\author{
C F Poets, V A Stebbens, J R Alexander, W A Arrowsmith, S A W Salfield, D P Southall
}

\begin{abstract}
Overnight 12 hour tape recordings of arterial oxygen saturation $\left(\mathrm{SaO}_{2}\right.$, pulse oximeter in the beat to beat mode), breathing movements, and airflow were made on 66 preterm infants (median gestational age 34 weeks, range 25-36) who had reached term ( 37 weeks) and were ready for discharge from the special care baby unit. No infant was given additional inspired oxygen during the study. The median baseline $\mathrm{SaO}_{2}$ was $99 \cdot 4 \%$ (range $88 \cdot 9-100 \%$ ). Eight infants had baseline $\mathrm{SaO}_{2}$ values below $97 \%$, the lowest value observed in a study on full term infants. All but one infant had shortlived falls in $\mathrm{SaO}_{2}$ to $\leqslant 80 \%$ (desaturations), which were more frequent (5.4 compared with $0.9 /$ hour) and longer (mean duration $1.5 \mathrm{com}$ pared with 1.2 seconds) than in full term infants. There was no evidence that gestational age at birth influenced the frequency or duration of desaturations among the preterm infants. The frequency of relatively prolonged episodes of desaturation $\left(\mathrm{SaO}_{2} \leqslant 80 \%\right.$ for $\geqslant 4$ seconds), however, decreased significantly with increasing gestational age $(0.5$, $0.4,0.2$, and 0.1 episodes/hour in infants at $\leqslant 32,33-34,35$, and 36 weeks' gestational age, respectively). Analysis of the respiratory patterns associated with such episodes showed that $5 \%$ occurred despite both continued breathing movements and continuous airflow. Five infants had outlying recordings: three had baseline $\mathrm{SaO}_{2}$ values of less than $95 \%$ $(88.9,92.7$, and $93.8 \%)$, and two had many prolonged desaturations (14 and 92/hour; median for total group $0 \cdot 2,95$ th centile $2 \cdot 3$ ). None of these five infants had been considered clinically to have a disorder of oxygenation.

Although these data are insufficient to provide information about outcome, we conclude that reference data on arterial oxygenation in preterm infants are important to enable the identification of otherwise unrecognised hypoxaemia.
\end{abstract}

Preterm infants have significantly more apnoeic pauses and periodic breathing when they reach term than infants who are born at term, ${ }^{1}$ particularly if they have a previous history of apnoea of prematurity. ${ }^{2}$ Apnoeic pauses may be triggered by chronic hypoxaemia, ${ }^{3}$ or may themselves cause episodic hypoxaemia. Short lived falls in oxygen saturation seem to be normal among infants. ${ }^{4}$ If we want to identify abnormal hypoxaemia, therefore, we need to know about normal variability in arterial oxygenation in this particular group of infants.
Currently, there is little knowledge about normal arterial oxygenation in infancy. In a previous study we analysed arterial oxygen saturation and breathing movements in healthy full term infants in their second month of life. ${ }^{4}$ In the present study, the same techniques have been applied to a group of preterm infants who were studied when they were ready for discharge from the special care baby unit and had reached at least 37 weeks' gestation. Two specific questions were asked: what is the influence of gestational age on the pattern of oxygenation, and (based on our study of term infants ${ }^{4}$ ) how does oxygenation differ between full term and preterm infants?

\section{Patients and methods}

Between August 1986 and July 1987 all preterm infants who were born at three maternity hospitals and who received special care immediately after birth had overnight tape recordings made of selected physiological variables. The study was carried out when infants were assessed as ready for discharge, and only on those who were considered to have a good prognosis for survival. A total of 305 infants fulfilled the criteria, and 261 (86\%) had parental consent for the investigation. The project was approved by the hospitals' ethics committees. For the purpose of this study, all 72 infants with gestational ages of 37 weeks or more at the time of discharge, and who underwent their recordings within the three days before discharge, were included in the analysis.

All 72 infants underwent 12 hour overnight recordings of arterial oxygen saturation $\left(\mathrm{SaO}_{2}\right)$ (Nellcor N100 with new software equivalent to N200 and specially modified to provide beat to beat data); each photoplethysmographic pulse waveform from a pulse oximeter (for the validation of the saturation signals); breathing movements from a volume expansion capsule (Graseby) or from respiratory inductance plethysmography (Studley Data Systems); and nasal airflow either through a thermistor (Yellow Springs Instruments) or from expired carbon dioxide sampling (Engström Eliza). The recordings were stored on tape (Racal FM4) and subsequently printed onto graph paper by an ink jet recorder at $3.2 \mathrm{~mm} / \mathrm{second}$. As the study was prospective and non-invasive the recordings were not used for clinical management.

Six recordings $(8 \%)$ gave poor quality oxygen saturation signals throughout and were removed from the study. Of the remaining 66 recordings, $31(47 \%)$ were done on the last day before discharge, $26(39 \%)$ two days, and eight (12\%) 
three days before discharge. Eight infants were receiving drug treatment at the time of the study: antibiotics $(n=6)$, diuretics $(n=1)$, and theophylline $(n=1)$. No infant was receiving additional inspired oxygen.

The recordings were analysed by two experienced workers without knowledge of the clinical history of the infants as described previously. ${ }^{4}$ In summary, the duration of artefact free $\mathrm{SaO}_{2}$ signal was measured. Periods of regular and non-regular breathing patterns were identified. The numbers of apnoeic pauses of 4 seconds or longer were counted. Episodes with three or more successive apnoeic pauses, each separated by less than 20 breaths, were classified as periodic apnoea.

Baseline oxygen saturation values were calculated for each episode of regular breathing by measuring the oxygen values at end inspiration for each of five successive breaths half way through the episode. In both breathing patterns the number of episodes in which $\mathrm{SaO}_{2}$ fell to $\leqslant 80 \%$ was counted, and the time that it remained $\leqslant 80 \%$ was measured during each episode. These episodes of desaturation were classified according to their relationship with an apnoeic pause. An association with an apnoeic pause was considered to be present if the desaturation began within 2-12 seconds of the onset of the apnoeic pause.

Prolonged desaturations $\left(\mathrm{SaO}_{2} \leqslant 80 \%\right.$ for $\geqslant 4$ seconds) were analysed separately; in full term infants $97 \%$ of all desaturations were shorter than 4 seconds. ${ }^{4}$ The breathing signals during each prolonged desaturation were analysed and classified according to the presence of: a pause in breathing movements; a pause in airflow only (minimum duration 4 seconds); a mixed pause with a combination of the first two; and continuous airflow with no pause in either breathing movements or airflow. If the desaturation occurred during a period in which the breathing signal was of poor quality the episode was classified as uninterpretable.

Clinical data were abstracted from the discharge summaries. Data concerning the infants' survival were collected from the National Health Service Register at the Office of Popula- tion Censuses and Surveys. Two infants died, both in the first year of life. One had a ventricular septal defect, and died at 5 months of age in the perioperative period after cardiac surgery, and one (who had developed asthma) died at 11 months in status asthmaticus. There was no death from the sudden infant death syndrome among the infants in this study.

To analyse the influence of gestational age at birth, results are presented for the total group of 66 infants and also divided into four subgroups, categorised arbitrarily before the results were examined, by gestational age (weeks) at birth: group $A, \leqslant 32(n=16)$; group $B, 33-34(n=18)$; group $C, 35(n=16)$; and group $D, 36(n=16)$.

Rates of occurrence of desaturations/hour of artefact free signal, and their mean durations, were calculated for each recording. The significance of differences was assessed using the Kruskal-Wallis test for the comparison between the subgroups of preterm infants with different gestational ages, the Wilcoxon rank sum test and Fisher's exact test for comparisons between preterm and full term infants, and the Wilcoxon matched pairs signed ranks test for comparisons between breathing patterns. Findings are given as the median (and range of individual mean values) for each variable.

\section{Results}

Table 1 shows that the infants in the four subgroups had different postnatal, but similar postconceptional, ages at the time of the study. A history of respiratory distress or apnoea of prematurity was more common among the infants who were less mature (table 2). Two infants had congenital heart disease: one had an aortopulmonary window, and one had a ventricular septal defect. Neither had outlying results for any of the variables studied.

The median duration of artefact free signal was $2 \cdot 0$ hours (range $0 \cdot 7-5 \cdot 5$ ) during regular breathing and $6 \cdot 1$ hours $(2 \cdot 7-8 \cdot 4)$ during nonregular breathing. These durations were similar in all subgroups (data not shown).

During regular breathing the median number of apnoeic pauses/hour was $5 \cdot 8(0 \cdot 0-19 \cdot 0)$, with two infants having no pauses during this pat-

Table 1 Clinical data of the infants studied, according to gestational age at birth. Figures are expressed as median (range) except where otherwise stated

\begin{tabular}{|c|c|c|c|c|c|}
\hline & \multicolumn{4}{|l|}{ Group } & \multirow[t]{2}{*}{ Total $(n=66)$} \\
\hline & $A(n=16)$ & $B(n=18)$ & $C(n=16)$ & $D(n=16)$ & \\
\hline $\begin{array}{l}\text { Gestational age at birth (weeks) } \\
\text { Male:female ratio } \\
\text { Birth weight (g) } \\
\text { Postnatal age at recording (days) } \\
\text { Postconceptional age at }\end{array}$ & $\begin{array}{l}29(25-32) \\
4: 12 \\
1115(700-1575) \\
78(32-106)\end{array}$ & $\begin{array}{l}33 \cdot 5(33-34) \\
12: 6 \\
1720(1200-2280) \\
26(18-52)\end{array}$ & $\begin{array}{l}35(35) \\
9: 7 \\
2030(1410-3260) \\
15(11-44)\end{array}$ & $\begin{array}{l}36(36) \\
10: 6 \\
2140(1375-2975) \\
15(5-65)\end{array}$ & $\begin{array}{l}34(25-36) \\
35: 31 \\
1822(700-3260) \\
24(5-106)\end{array}$ \\
\hline recording (weeks) & $39(37-43)$ & $37 \cdot 5(37-41)$ & $37(37-42)$ & $39(37-46)$ & $38(37-46)$ \\
\hline
\end{tabular}

Table 2 Clinical histories of infants according to gestational age

\begin{tabular}{llllll}
\hline & Group & & & Total (n=66) \\
\cline { 2 - 5 } & $A(n=16)$ & $B(n=18)$ & $C(n=16)$ & $D(n=16)$ & 36 \\
Gestational age at birth (weeks) & $\leqslant 32$ & $33-34$ & 35 & 2 & $25-36$ \\
Product of multiple pregnancy & 4 & 2 & 8 & 5 & 10 \\
Respiratory distress syndrome & 13 & 9 & 1 & 0 & 25 \\
Positive pressure ventilation & 13 & 7 & 1 & 0 & 17 \\
History of apnoea of prematurity & 11 & 5 & &
\end{tabular}




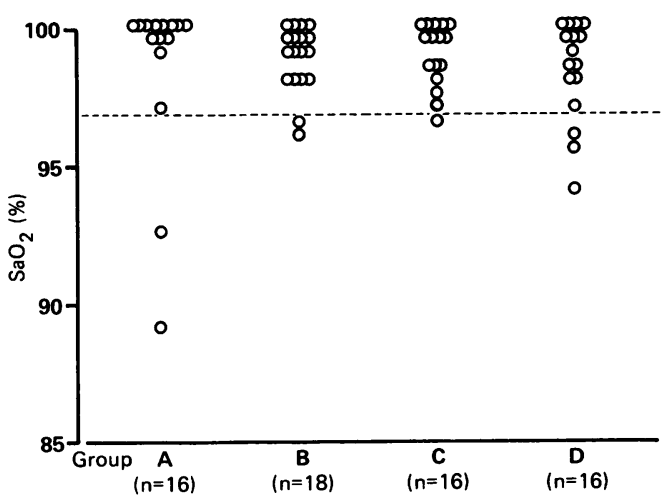

Figure 1 Distribution of baseline measurements of $\mathrm{SaO}_{2}$ in groups of different gestational ages (weeks) at birth: group $A$, $\leqslant 32 ; B, 33-34 ; C, 35 ;$ and $D, 36$. Dotted line represents the lowest value recorded in 67 full term infants (97\%).

tern. All infants had pauses during non-regular breathing, with a median of $30.8(0.5-155 \cdot 2)$ pauses/hour. Periodic apnoea occurred in 63 $(95 \%)$ infants, with a median of $14.0(0.0$ $144.0)$ pauses/hour in this pattern. Again, values were similar in the groups with different gestational ages at birth (data not shown).

The median baseline $\mathrm{SaO}_{2}$ was $99 \cdot 4 \%$ (88.9 100 ). The fifth centile was $94 \cdot 3 \%$. Analysis of variability in baseline $\mathrm{SaO}_{2}$ measurements within individual recordings showed a median SD of $0.8 \%$ (range $0-3 \cdot 2 \%$ ). The average variability within baseline $\mathrm{SaO}_{2}$ measurements between different episodes of regular breathing in the same recording was thus four times higher than in the full term infants studied previously. ${ }^{4}$

Eight infants had a baseline $\mathrm{SaO}_{2}$ value below $97 \%$, the lowest level observed in normal full term infants (fig 1). ${ }^{4}$ None of the three infants who had values below the fifth centile had been considered clinically hypoxaemic: the first, with a baseline $\mathrm{SaO}_{2}$ of $93.8 \%$, had never received additional inspired oxygen. The second, with a baseline of $92 \cdot 7 \%$, had been oxygen dependent until 72 days of age, but was not thought clinically to require it at the time of discharge. The infant with the lowest baseline $\mathrm{SaO}_{2}(88.9 \%)$ had a gestational age of 31 weeks and had been ventilated for three days because of mild respiratory distress syndrome. She had no history of apnoea of prematurity and was clinically well. Because her $\mathrm{SaO}_{2}$ was below $80 \%$ during a substantial part of the recording, it was excluded from further analysis of episodic desaturation below $80 \%$.

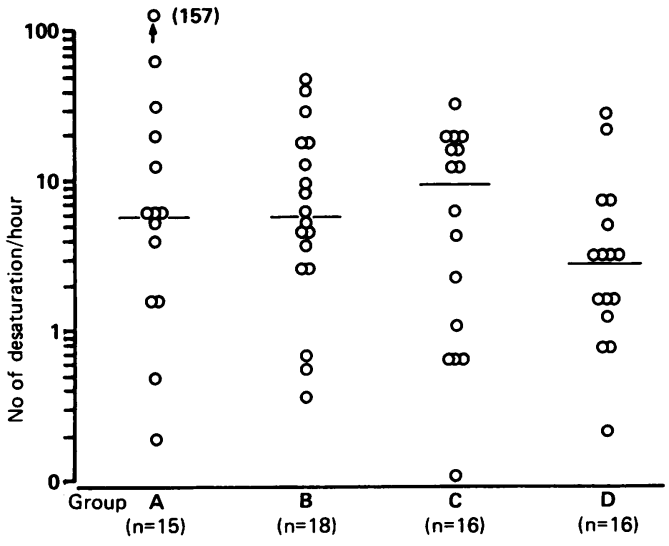

Figure 2 Distribution of desaturations $\left(\mathrm{SaO}_{2} \leqslant 80 \% /\right.$ hour $)$ in groups of different gestational ages (weeks) at birth: group $A, \leqslant 32 ; B, 33-34 ; C, 35$; and $D, 36$. Note logarithmic scale on the y axis. Horizontal bars indicate median in each group. Values for desaturations could not be obtained for one infant in group $A$.

All but one recording contained episodes during which $\mathrm{SaO}_{2}$ fell transiently to $80 \%$ or less (table 3). The frequency and mean duration of these desaturations were similar in the groups with different gestational age (table 3, fig 2). The duration of the longest desaturation observed in each recording, as well as the proportion of apnoeic pauses that was followed by a desaturation, decreased with increasing gestational age, but the differences between the groups were not significant (table 3 ). There were, however, significant differences for all variables between different breathing patterns: desaturations were more frequent and were longer during non-regular than during regular breathing, and the proportion of apnoeic pauses followed by a desaturation was also higher during non-regular breathing (table 3). All variables differed significantly from those previously obtained in full term infants (table 4).

Analysis of prolonged desaturations $\left(\mathrm{SaO}_{2}\right.$ $\leqslant 80 \%$ for $\geqslant 4$ seconds) showed that 44 infants $(68 \%)$ had a total of 822 such episodes, with a median frequency of $0.2(0.0-92.4)$ per hour (fig 3). This frequency decreased significantly with increasing gestational age $(p<0.02)$. The analysis of the associated breathing pattern showed that most of the prolonged desaturations (534 (65\%) in 28 infants) followed pauses during periodic apnoea; and $144(18 \%)$ in 31 infants followed isolated apnoeic pauses, almost all of these occurring during non-regular breathing.

Table 3 Results of arterial oxygen saturation measurements. Values are expressed as median (range) except where otherwise stated; ${ }^{*} p<0 \cdot 05,{ }^{* *} p<0 \cdot 01$, ${ }_{* * *} p<0.001$, regular compared with non-regular breathing patterns

\begin{tabular}{|c|c|c|c|c|c|c|}
\hline & \multirow{2}{*}{$\begin{array}{l}\text { Breathing } \\
\text { pattern }\end{array}$} & \multicolumn{4}{|l|}{ Group } & \multirow[t]{2}{*}{ Total $(n=65)$} \\
\hline & & $A(n=15)$ & $B(n=18)$ & $C(n=16)$ & $-D(n=16)$ & \\
\hline $\begin{array}{l}\text { Gestational age at birth } \\
\text { (weeks) } \\
\text { No of desaturations } \\
\left(\mathrm{SaO}_{2} \leqslant 80 \%\right) / \text { hour } \\
\text { Mean duration of desat- } \\
\text { urations (seconds) }\end{array}$ & $\begin{array}{l}\text { Regular } \\
\text { Non-regular } \\
\text { Regular } \\
\text { Non-regular }\end{array}$ & $\begin{array}{l}\leqslant 32 \\
0 \cdot 4(0 \cdot 0-40 \cdot 1)^{* * *} \\
7 \cdot 6(0 \cdot 2-164 \cdot 9) \\
0 \cdot 9(0 \cdot 3-3 \cdot 2)(n=8)^{* *} \\
1 \cdot 7(0 \cdot 7-4 \cdot 4)(n=15)\end{array}$ & $\begin{array}{l}33-34 \\
0.0(0 \cdot 0-12 \cdot 0)^{* * *} \\
8 \cdot 8(0 \cdot 3-63 \cdot 4) \\
1 \cdot 1(0 \cdot 3-2 \cdot 7)(n=7)^{*} \\
1.6(0 \cdot 5-3 \cdot 3)(n=18)\end{array}$ & $\begin{array}{l}35 \\
0 \cdot 0(0 \cdot 0-2 \cdot 7)^{* * *} \\
12 \cdot 0(0 \cdot 0-41 \cdot 7) \\
1.9(0 \cdot 6-2 \cdot 0)(n=7) \\
1.6(0 \cdot 6-3 \cdot 3)(n=15)\end{array}$ & $\begin{array}{l}36 \\
0 \cdot 0(0 \cdot 0-4 \cdot 9)^{* * *} \\
3 \cdot 9(0 \cdot 0-29 \cdot 5) \\
0 \cdot 9(0 \cdot 3-1 \cdot 2)(n=5) \\
1 \cdot 3(0 \cdot 6-2 \cdot 4)(n=15)\end{array}$ & $\begin{array}{l}25-36 \\
0 \cdot 0(0 \cdot 0-40 \cdot 1)^{* * *} \\
7 \cdot 2(0 \cdot 0-164 \cdot 9) \\
1 \cdot 1(0 \cdot 3-3 \cdot 2)(n=27)^{* * * *} \\
1 \cdot 5(0 \cdot 5-4 \cdot 4)(n=63)\end{array}$ \\
\hline $\begin{array}{l}\text { Duration of longest desat- } \\
\text { uration (seconds) }\end{array}$ & $\begin{array}{l}\text { Regular+ } \\
\text { non-regular }\end{array}$ & $7 \cdot 2(1 \cdot 1-26 \cdot 9)$ & $7 \cdot 7(0 \cdot 8-26 \cdot 9)$ & $5.0(0.3-13.8)$ & $3.9(0.3-17 \cdot 0)$ & $5 \cdot 1(0 \cdot 3-26 \cdot 9)$ \\
\hline $\begin{array}{l}\text { No of desaturations } \geqslant 4 \\
\text { seconds/hour } \\
\text { Percentage of apnoeic pauses } \\
\text { that were followed by a } \\
\text { desaturation }\end{array}$ & $\begin{array}{l}\text { Regular }+ \\
\text { non-regular } \\
\text { Regular } \\
\text { Non-regular }\end{array}$ & $\begin{array}{l}0.5(0 \cdot 0-92 \cdot 4) \\
2(0-100) \\
12(0-96)\end{array}$ & $\begin{array}{l}0 \cdot 4(0 \cdot 0-14 \cdot 2) \\
0(0-64)^{* * *} \\
18(0-70)\end{array}$ & $\begin{array}{l}0 \cdot 2(0 \cdot 0-2 \cdot 3) \\
0(0-33)^{* *} \\
11(0-43)\end{array}$ & $\begin{array}{l}0 \cdot 1(0 \cdot 0-0 \cdot 4) \\
0(0-86)^{* *} 4 \\
6(0-58)\end{array}$ & $\begin{array}{c}0 \cdot 2(0 \cdot 0-92 \cdot 4) \\
0(0-100)^{* * * *} \\
12(0-96)^{* * * *}\end{array}$ \\
\hline
\end{tabular}


Table 4 Comparison of results between full term and preterm infants. Figures are expressed as median (range) except where otherwise indicated. Values for desaturations could not be obtained in one preterm infant.

\begin{tabular}{lccc}
\hline & $\begin{array}{l}\text { Full term } \\
\text { infants }(n=67)\end{array}$ & $\begin{array}{l}\text { Preterm } \\
\text { infants }(n=66)\end{array}$ & $p$ Value \\
\hline Age at recording (days) & $39(29-54)$ & $23(5-106)$ & Not applicable \\
No of apnoeic pauses/hour & $6 \cdot 8(0 \cdot 4-72 \cdot 0)$ & $25(1 \cdot 0-147 \cdot 3)$ & $<0 \cdot 0001$ \\
No (\%) infants with periodic apnoea & $33(49 \cdot 3)$ & $63(94)$ & $<0 \cdot 0001$ \\
Baseline SaO, measurement $(\%)$ & $99 \cdot 8(97 \cdot 0-100)$ & $99 \cdot 4(88 \cdot 9-100)$ & $<0 \cdot 01$ \\
No (\%) infants with SaO $\leqslant 80 \%$ & $54 / 67(81)$ & $64 / 65(99)$ & $<0 \cdot 02$ \\
No of desaturations/hour & $0 \cdot 9(0 \cdot 0-15 \cdot 1)$ & $5 \cdot 4(0 \cdot 0-156 \cdot 5)$ & $<0 \cdot 0001$ \\
Mean duration of desaturation (seconds) & $1 \cdot 2(0 \cdot 3-2 \cdot 2)$ & $1 \cdot 5(0 \cdot 3-4 \cdot 4)$ & $<0 \cdot 001$ \\
Duration of longest desaturation (seconds) & $2 \cdot 4(0 \cdot 3-8 \cdot 6)$ & $5 \cdot 1(0 \cdot 0-26 \cdot 9)$ & $<0 \cdot 0001$ \\
\hline
\end{tabular}

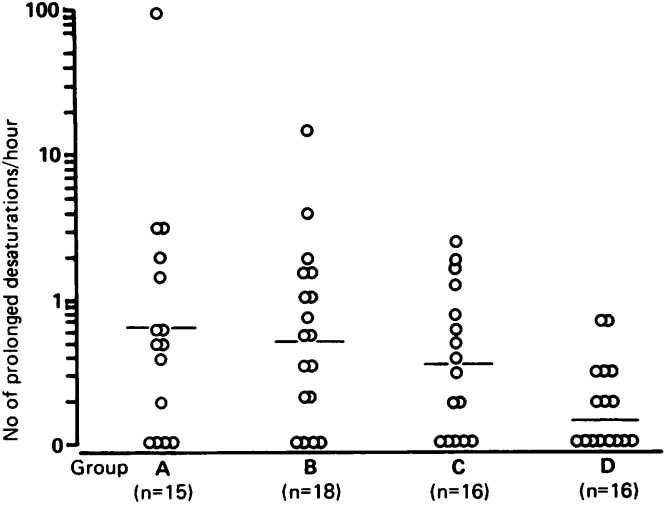

Figure 3 Distribution of prolonged desaturations $\left(\mathrm{SaO}_{2}\right.$ $\leqslant 80 \%$ for $\geqslant 4$ seconds/hour) in groups of different gestational ages (weeks) at birth: group $A, \leqslant 32 ; B, 33-34 ; C, 35 ;$ and $D, 36$. Note logarithmic scale on the y axis. Horizontal bars indicate median in each group. Values for desaturations could not be obtained for one infant in group $A$.

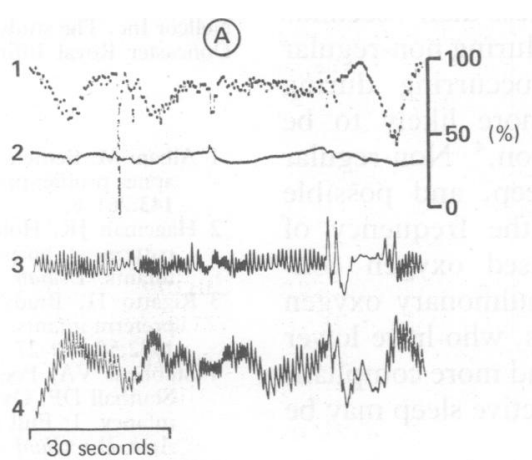

(B)
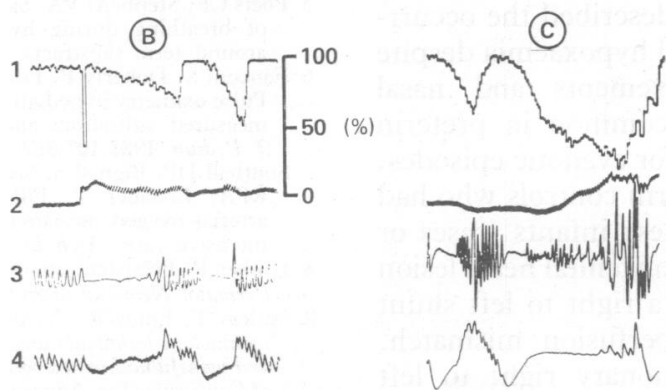

Figure 4 Examples of the different breathing patterns during prolonged desaturations: 1 = arterial oxygen saturation; $2=$ photoplethysmographic waveform, $3=$ breathing movements (pressure capsule); and $4=$ nasal airflow (thermistor). (A) shows two episodes of desaturation despite continued breathing movements and airflow, followed by a desaturation associated with a short apnoeic pause. The shape of the saturation signal is similar during both patterns. $(B)$ shows two pauses in breathing movements and airflow of 15 and 7 seconds duration, respectively. $(C)$ shows a mixed pause (21 seconds) with a pause in breathing movements and airflow that is followed by cessation of airflow only.

Forty one ( $5 \%$ ) were associated with an absence of airflow, 12 of these being mixed pauses. Thirty seven prolonged desaturations $(5 \%)$ in 17 infants occurred despite the continuation of both breathing movements and airflow. In the remaining $7 \%$ airflow signals were uninterpretable. Examples of the different breathing patterns during prolonged desaturations are shown in fig 4.

There were two infants who had values far outside the range of all other infants (fig 3 ). One infant, who had a total of 104 prolonged desaturations $(14 \cdot 2 /$ hour $)$, had a gestational age of 34 weeks and had had recurrent apneoa and bradycardia that were reported to have ceased a week before discharge. Her baseline $\mathrm{SaO}_{2}$ was $98.9 \%$ The other infant, who had a total of 382 prolonged desaturations (92.4/hour), 362 of them during periodic apnoea, was born at 26 weeks' gestation (birth weight $775 \mathrm{~g}$ ), and had had positive pressure ventilation for the first four weeks of life. Her baseline $\mathrm{SaO}_{2}$ was $97 \cdot 1 \%$. She was also the infant with the highest number of short desaturations, and the only infant in whom more than $95 \%$ of apnoeic pauses were followed by a desaturation during both regular and non-regular breathing patterns. Both infants were clinically well at the time of the recordings.

\section{Discussion}

The present study, in which we used a pulse oximeter in the beat to beat mode that has been validated against arterial line measurements, ${ }^{67}$ provides the first reference data for $\mathrm{SaO}_{2}$ in preterm infants. The infants studied were a heterogeneous group covering a wide range of gestational ages at birth, and different medical histories, because we wanted to provide representative data for preterm infants leaving special care. We were therefore careful not to apply too restrictive entry criteria for the infants that were enrolled in this study. So that the data could be compared, however, it was necessary to include only infants who had reached term at the time of their discharge.

There were relatively small differences in the number and duration of desaturations between subgroups with different gestational ages at birth but similar postconceptional ages at the time of study. This finding is in agreement with that of Hinkes on breathing movements in preterm infants; he also showed a wide scattering in the number of apnoeic pauses in infants with different gestational ages. ${ }^{8}$ Our data, however, show that the frequency of prolonged desaturations increased with decreasing gestational age at birth (fig 3). This, and the fact that there were highly significant differences for all variables between these preterm infants and the full term infants (table 4), suggest that gestational age at birth may have some influence on the 
development of stability in arterial oxygenation. ${ }^{4}$ This influence, however, is overlaid by the large interindividual variability in the frequency of desaturations in this group of infants. The comparison with full term infants is additionally compromised by the fact that the full term infants were older at the time of study and had a narrower age range, specifically omitting the neonatal period. The indications that maturity at birth is an independent factor for the developmental of stability in oxygenation cannot therefore be confirmed by these data. Further studies of larger numbers of infants are necessary to answer this question.

Interestingly, with few exceptions, the preterm infants had baseline values of $\mathrm{SaO}_{2}$ in the same range at the full term infants. ${ }^{4}$ This means that during stable conditions most preterm infants had normal $\mathrm{SaO}_{2}$ The variability in baseline $\mathrm{SaO}_{2}$ in the same recording, however, was considerable. This suggests that making only one measurement during quiet sleep may not provide reliable information about baseline $\mathrm{SaO}_{2}$ in infants born before full term.

The present data clearly show the influence of breathing pattern on arterial oxygenation. During regular breathing, which is highly correlated with the state of quiet sleep, ${ }^{9}$ most of the infants did not have any episodes of desaturation, and when episodes did occur, they were usually short (in $95 \%$ of infants the longest desaturation during regular breathing was less than 4 seconds long). The opposite was true during non-regular breathing; apnoeic pauses occurring during non-regular breathing are more likely to be associated with a desaturation. ${ }^{4}$ Non-regular breathing includes active sleep, and possible reasons for an increase in the frequency of desaturations include increased oxygen consumption and reduced intrapulmonary oxygen stores. ${ }^{1011}$ In preterm infants, who have lower functional residual capacity and more compliant chest walls, the influence of active sleep may be even more pronounced. ${ }^{12}$

In a previous study we described the occurrence of intermittent arterial hypoxaemia despite continued breathing movements and nasal airflow. ${ }^{5}$ This was most common in preterm infants being investigated for cyanotic episodes, but also in two of 16 preterm controls who had no symptoms. None of these infants (cases or controls) had a structural congenital heart lesion that could have produced a right to left shunt and resultant ventilation/perfusion mismatch. An intermittent intrapulmonary right to left shunt was, therefore, considered to be the most likely cause of these hypoxaemic episodes. ${ }^{5} 13$ The analysis of breathing patterns during prolonged desaturations performed in the present study confirms our previous observation that the potential to develop a mismatch between ventilation and perfusion may also be present in clinically well preterm infants.

The large interindividual variability in the frequency of short lived desaturations reduces their usefulness as markers of abnormal respiratory pathophysiology. The frequency of prolonged desaturations, and the baseline $\mathrm{SaO}_{2}$ values, however, showed less variability between subjects and may therefore serve as indicators for hypoxaemia. Using these variables, five infants in this study were identified as clear outliers at the time of their discharge from hospital: three with baseline $\mathrm{SaO}_{2}$ values below $95 \%$ (one only $89 \%$ ) and two with large numbers of prolonged desaturations. Our sample is not large enough to provide information about the outcome of these infants. There is evidence, however, that chronic or acute intermittent hypoxaemia may be a contributing factor to sudden infant death, ${ }^{13-15}$ and that chronic hypoxaemia may reduce the amount of weight gained by preterm infants. ${ }^{16}$ This condition should therefore be identified and treated. Further prospective studies on the reproducibility and prognostic significance of outlying results should be done, however, before similar long term recordings of arterial oxygen saturation and breathing patterns can be advocated for all preterm infants before discharge from special care baby units.

We thank the workers who gave careful technical effort to the study: Mary Gray, Gill Crowther, Jean Tait, Barbara Neville, and Pat Allison who took the recordings, Pauline Mills and and Pat Allison who took the recordings, Pauline Mills and Jackie Kelly who made the measurements, and Linda Alexander
and Vivienne Taylor who carried out basic analyses. Thanks also to the medical, nursing, secretarial, and medical records staff at to the medical, nursing, secretarial, and medical records staff at
Doncaster Royal Infirmary and Rotherham and Barnsley District Doncaster Royal Infirmary and Rotherham and Barnsley District
General Hospitals. Particular thanks to Dr Bridson and the famiGeneral Hospitals. Particular thanks to Dr Bridson and the fami-
lies of the babies being given special care at these hospitals. Technical advice was given by Dr W New, and computing facilities were donated by Hewlett Packard Ltd and Ashton-Tate Ltd. Dr Poets was funded by the Deutsche Forschungsgemeinschaft, Bonn, Germany, Mrs Stebbens by the Nuffield Foundation, and Dr Southall by the National Heart and Chest Hospitals, and Nellcor Inc. The study was supported by the Cot Death Fund at Doncaster Royal Infirmary.

1 Albani M, Bentele KHP, Budde C, Schulte FJ. Infant sleep apnea profile: preterm vs. term infants. Eur f Pediatr 1985; 143:261-8

2 Hageman JR, Holmes D, Suchy S, Hunt CE. Respiratory pattern at hospital discharge in asymptomatic preterm infants. Pediatr Pulmonol 1988;4:78-83.

3 Rigatto H, Brady JB. Periodic breathing and apnea in preterm infants. II. Hypoxia as a primary event. Pediatrics 1972;50:219-27.

4 Stebbens VA, Poets CF, Alexander JA, Arrowsmith WA, Southall DP. Oxygen saturation and breathing patterns in infancy. 1: Full term infants in the second month of life. Arch Dis Child 1991;66:569-73.

5 Poets CF, Stebbens VA, Samuels MP, Southall DP. Patterns of breathing during hypoxaemia in preterm infants at around term (abstract). Early Hum Dev 1990;22:107-8.

6 Fanconi S, Doherty P, Edmonds JF, Barker GA, Bohn DJ. Pulse oximetry in pediatric intensive care: comparison with measured saturations and transcutaneous oxygen tension. $\mathcal{F}$ Pediatr 1985;107:362-6.

7 Southall DP, Bignall S, Stebbens VA, Alexander JR, Rivers RPA, Lissauer T. Pulse oximeter and transcutaneous arterial oxygen measurements in neonatal and paediatric intensive care. Arch Dis Child 1987;62:882-8.

8 Hinkes P. Persistent apnea and bradycardia of prematurity. Perinatol Neonatol 1984;8:17-25.

9 Apders T, Emde R, Parmelee A. A manual of standardized terminology techniques and criteria for scoring of states of sleep and wakefulness in newborn infants. Los Angeles: University of California (Los Angeles) Brain Informatin Service, 1971.

10 Stothers JK, Warner RM. Oxygen consumption and neonatal sleep states. $\mathcal{f}$ Physiol (Lond) 1978;278:435-40.

11 Henderson-Smart DJ, Read DJC. Reduced lung volume during behavioral active sleep in newborn. I Appl Physiol 1979;46:1081-5.

12 Stark AR, Cohlan BA, Waggener TB, Frantz ID III, Kosch PC. Regulation of end-expiratory lung volume during sleep
in premature infants. $\mathcal{F}$ Appl Physiol 1987;62:1117-23.

13 Southall DP, Samuels MP, Talbert DG. Recurrent cyanotic episodes with severe arterial hypoxaemia and intrapulmonepisodes with severe arterial hypoxaemia and intrapulmonary shunting: a mechanis
Child 1990;65:953-61.

14 Guntheroth WG, Kawabori I, Breazeale DG, Garlinghouse LE, van Hoosier GL. The role of respiratory infection in LE, van Hoosier GL. The role of respiratory infection in

15 Rognum TO, Saugstad OD, Øyasoeter S, Olaisen B. Rognum TO, Saugstad OD, Øyasoeter S, Olaisen B.
Elevated levels of hypoxanthine in vitreous humour indiElevated levels of hypoxanthine in vitreous humour indicate prolonged cerebral hypoxia in victims of
death syndrome. Pediatrics 1988;82:615-8.

16 Groothuis JR, Rosenberg AA. Home oxygen promotes weight gain in infants with bronchopulmonary dysplasia. Am $\mathcal{J}$ Dis Child 1987;141:992-5. 